\title{
LANGMUIR ISOTHERM MODELS APPLIED TO THE SORPTION OF ACID DYES FROM EFFLUENT ONTO POLYAMIDE NANOFIBERS
}

\author{
Yan Wang, Jakub Wiener, Guocheng Zhu
}

Department of Textile Material Engineering, Faculty of Textile, Technical University of Liberec, Studentska 1402/2, 461 17, Liberec 1, Czech Republic E-mail: yan.wang@tul.cz

\begin{abstract}
:
The ability of polyamide 6 nanofibers membrane (P6NM) to remove acid dyes from effluent solution by adsorption has been studied. Equilibrium isotherms for the adsorption of three acid dyes, Acid blue 41 (AB41), Acid blue 78 (AB78), and Acid yellow 42 (AY42), on P6NM were measured experimentally. Simulated wastewater of acid dyes with the concentration of $10 \mathrm{mg} / \mathrm{L}$ for sorption process electrospun polyamide 6 with mass per unit area $12 \mathrm{~g} / \mathrm{m}^{2}$ was used as the sorbent material. Ten sets of P6NM were dipped in separate simulated effluent. The weight of the original P6NM and the concentration of left solution were detected. Results were analyzed by the Langmuir equation using a linearized correlation coefficient. And it showed that all the dyes tested could follow the Langmuir adsorption isotherm, which gave excellent correlation for all the dyes.
\end{abstract}

\section{Keywords:}

Polyamide nanofibers, acid dyes, wastewater, Langmuir

\section{Introduction}

The extensive use of dyes in textiles, printing, dyeing, and food plants has produced a large amount of dye wastewater. The total dye consumption of the textile industry worldwide is in excess of $10^{7} \mathrm{~kg} /$ year and an estimated $90 \%$ of this ends up on fabrics. Consequently, more than $10^{6} \mathrm{~kg} / \mathrm{year}$ of dyes are discharged into waste streams by the textile industry [1]. The release of some dyes into water streams results in a serious environmental impact; many of the dyes cause health problems such as allergic dermatitis, cancer, skin irritation and also mutation in humans [2-4]. In addition, dyes absorb sunlight within water media resulting in the prevention of photosynthesis of aquatic plants. And the water including dyes exert an adverse effect on fish life [2]. Therefore, the treatment of wastewater has been a vital issue in environmental protection since some dyes and their degradation products are known carcinogens and others probable carcinogens and toxic [2,4-6].

The treatment of dye effluents is rather not easy because of their synthetic origins and mainly because of their aromatic structure, which are biologically non-degradable. Various physiochemical methods such as tricking filter, activated sludge, chemical coagulation, carbon adsorption, and photodegradation processes [7-11] have been investigated extensively for the dye removal. Among all these chemical and physical methods, sorption process has been used as one of the effective techniques successfully employed for color removal $[9,12,13]$. Activated carbon is regarded as the effective, however, expensive adsorbent due to its high cost of manufacturing and generation; others including peat, chitin, silica, and some agriculture waste have also been utilized but the sorption capacities of the above adsorbents are not very high. To improve the efficiency of sorption process, it is necessary to develop cheap and easily available adsorbents with high sorption capacities [12]. Therefore, to select one cost-effective method to remove the dyes, more and more attention has been paid to nanostructure materials such as nanofiber membranes, which have low density, small pore size, interconnected open pore structure, and a large surface area-tovolume ratio compared with non-wovens. Nanofiber membranes not only enable high removal efficiencies but also allow reuse of water and some of the valuable waste constituents (specifically dyes and auxiliary chemicals) [2,5,14-18].

To describe and compare the sorption properties of different dyestuffs on nanofiber membranes, we performed the sorption experiment with polyamide 6 nanofibers membrane (P6NM) and the simulated effluent with three acid dyes namely Acid blue 41 (AB41), Acid blue 78 (AB78), and Acid yellow 42 (AY42). The equilibrium of dye sorption was analyzed and compared with Langmuir adsorption isotherm [19].

\section{Materials and method}

\section{Adsorbent}

The P6NM that was used as a sorbent during sorption filtration was purchased from the company Elmarco s.r.o (Czech Republic), with the mass per unit area of $12 \mathrm{~g} / \mathrm{m}^{2}$ (Figure 1). The pieces of $30 \mathrm{~mm} \times 30 \mathrm{~mm}$ were used for all the experiments. The filtration unit was the normal unit used for membrane filtration for laboratory scales.

\section{Adsorbate}

Three dyes were used in this study namely acid dyes C.I AB41, C.I AB78, and C.I AY42; they were received from Technical 
University of Liberec, and their structures and scientific properties are shown in Figure 2 and Table 1, respectivley.

\section{Equilibrium sorption studies}

Ten dye solutions of $10 \mathrm{mg} / \mathrm{L}$, of the same volume of $100 \mathrm{ml}$, were prepared such that in the first solution one piece of P6NM was used, in the second solution, two pieces, the same was applied up to ten pieces of P6NM.

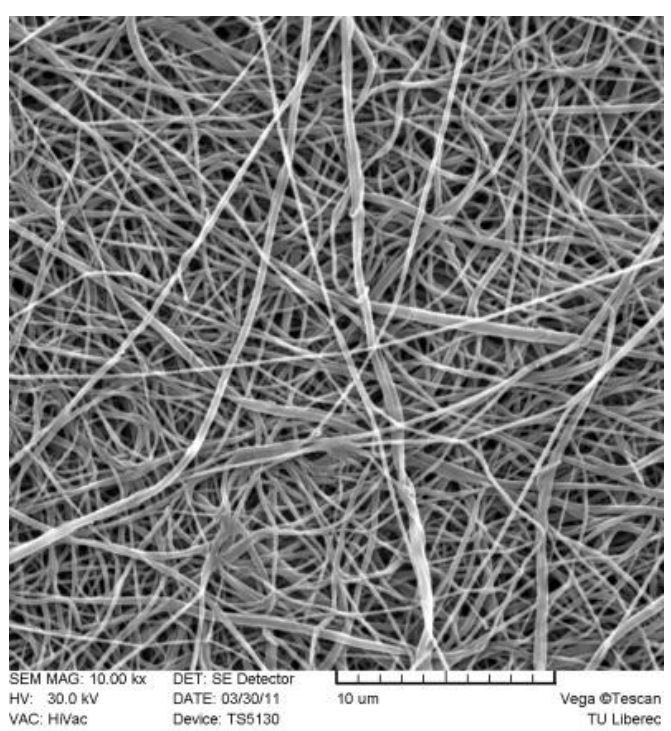

Figure 1. Polyamide nanofibers with fiber diameter around $300 \mathrm{~nm}$.
The flasks were sealed for 10 days at a temperature of $20 \pm 1{ }^{\circ} \mathrm{C}$ until equilibrium was reached. At time $t=0$ and equilibrium, the dye concentrations of the solutions were measured by the spectrometer spekol 11, zp100027. These data were used to calculate the adsorption capacity, $C_{\mathrm{s}}$, of the adsorbent. Finally, $C_{\mathrm{s}}$ was plotted against equilibrium concentration, $C_{\mathrm{L}}$.

\section{Results and discussion}

The results from Figure 3 were used for the determination of the sorption isotherm, which in this case was the Langmuir isotherm to best describe the results scientifically. Using equation:

$$
C_{S}=\frac{K C_{L} S}{1+K C_{L}}
$$

where $C_{\mathrm{s}}$ is the sorption capacity of mass of dye per mass of fiber $(\mathrm{mg} / \mathrm{g}), K$ is the affinity between sorbate and sorbent $(\mathrm{L} / \mathrm{g}), C_{\mathrm{L}}$ is the concentration in liquor $(\mathrm{g} / \mathrm{L}), S$ is the maximum amount of dye that can be adsorbed $(\mathrm{mg} / \mathrm{g})$.

The linear form of the equation was used to determine the constants $S$ and $K$ from the intercept and the slope from Figure 4:

$$
\frac{1}{C_{S}}=\frac{1}{C_{L}} \frac{1}{K S}+\frac{1}{S}
$$<smiles>CC(=O)N(C)c1ccc(Nc2cc(S(=O)(=O)[O-])c(N)c3c2C(=O)c2ccccc2C3=O)cc1</smiles>

C.I Acid blue 41 (AB41)

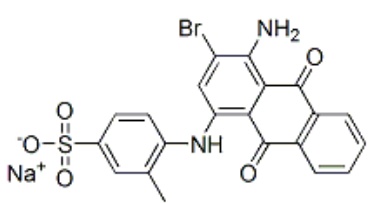

C.I Acid blue 78 (AB78)

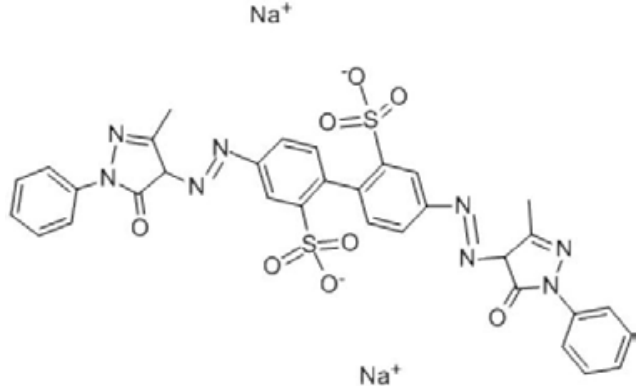

C.I Acid yellow 42 (AY42)

Figure 2. The molecular structures of the three selected dyestuffs.

\begin{tabular}{|c|c|c|c|}
\hline Abbreviation & Chemical name & $\begin{array}{c}\text { Molecular weight } \\
\text { (g/mol) }\end{array}$ & Molecular formula \\
\hline AB41 & $\begin{array}{l}\text { 2-Anthracene sulfonic acid, 4-[[4-(acetylmethylamino)phenyl] } \\
\text { amino]-1-amino-9,10-dihydro-9,10-dioxo-,sodium salt (1:1) }\end{array}$ & 487 & $\mathrm{C}_{23} \mathrm{H}_{18} \mathrm{~N}_{3} \mathrm{NaO}_{6} \mathrm{~S}$ \\
\hline AB78 & $\begin{array}{l}\text { Benzene sulfonic acid, 2-[(4-amino-3-bromo-9,10-dihydro- } \\
\text { 9,10-dioxo-1 anthracenyl)amino]-5-methyl-,sodium salt }(1: 1)\end{array}$ & 509 & $\mathrm{C}_{21} \mathrm{H}_{15} \mathrm{BrN}_{2} \mathrm{O}_{5} \mathrm{SNa}$ \\
\hline AY42 & $\begin{array}{l}\text { Oxo-[1-phenyl-1H-pyrazol-4-yl)azo]-[1,1ф-biphenyl]-2,2ф- } \\
\text { disulfonate }\end{array}$ & 759 & $\mathrm{C}_{32} \mathrm{H}_{24} \mathrm{~N}_{8} \mathrm{Na}_{2} \mathrm{O}_{8} \mathrm{~S}_{2}$ \\
\hline
\end{tabular}

Table 1. The physical and chemical characteristics of selected dyestuffs. 
The sorption process was confirmed to fit the above equation. The experimental points are shown in Figure 4 and compared with the linear regression lines.

The straight line graph in Figure 4 is obtained for the determination of the constants.

The values in Table 2 were then used for the construction of the Langmuir curve, which was then compared with the experimental points for each of the three dyes used and these are shown in Figure 5.

The results in Table 2, obtained from the straight line version of Langmuir isotherm, showed that the constant $S$ (maximum amount of dye that can be adsorbed) was the highest for AB41 and the other two dyes had almost half of the value of $A B 41$; this is the reflection of that in almost all cases, the AB41 will always have higher values of sorption capacity, as this is directly proportional to the $S$ values, thus more percentage of AB41 is exhausted than for the other two dyes. The table also shows the values of $K, A B 78$ had the highest value followed by AY42 and then AB41. Even though these dyes had highest affinity, they had lower $S$ values.

The graphs from Figure 5 show the experimental results and the results for the theoretical model. All the graphs were

Table 2. The results of constants for different dyes using linear graphs.

\begin{tabular}{|c|c|c|c|}
\hline Dye & $\mathbf{S}(\mathbf{m g} / \mathbf{g})$ & $\mathbf{K}(\mathbf{L} / \mathbf{g})$ & $\mathbf{R}^{\mathbf{2}}$ \\
\hline $\mathrm{AB} 41$ & 43.9 & 2561.5 & 0.978 \\
\hline $\mathrm{AB} 78$ & 20.1 & 17300.6 & 0.982 \\
\hline $\mathrm{AY} 42$ & 24.2 & 6779.8 & 0.981 \\
\hline
\end{tabular}

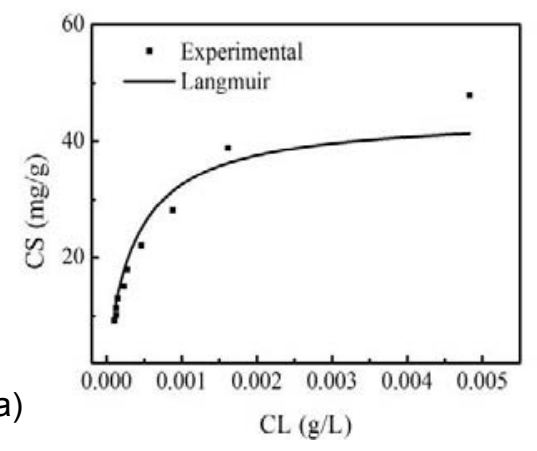

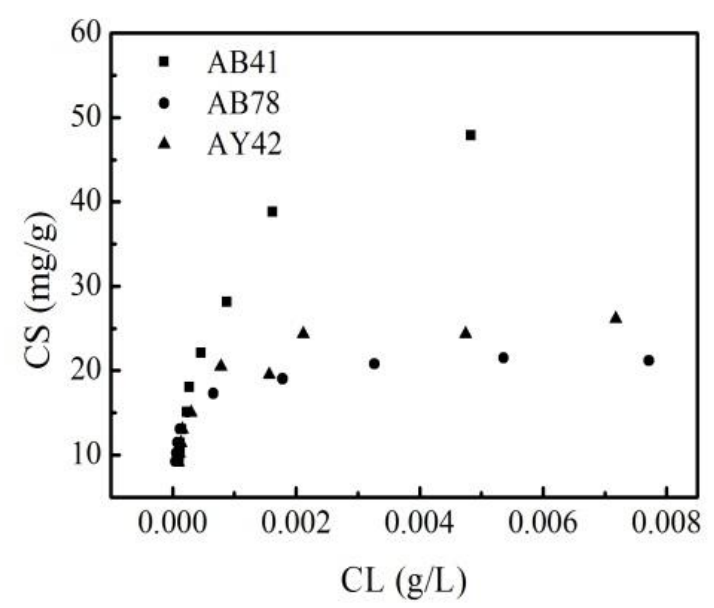

Figure 3. Sorption capacity (CS) and the concentration of the filtrate at equilibrium.

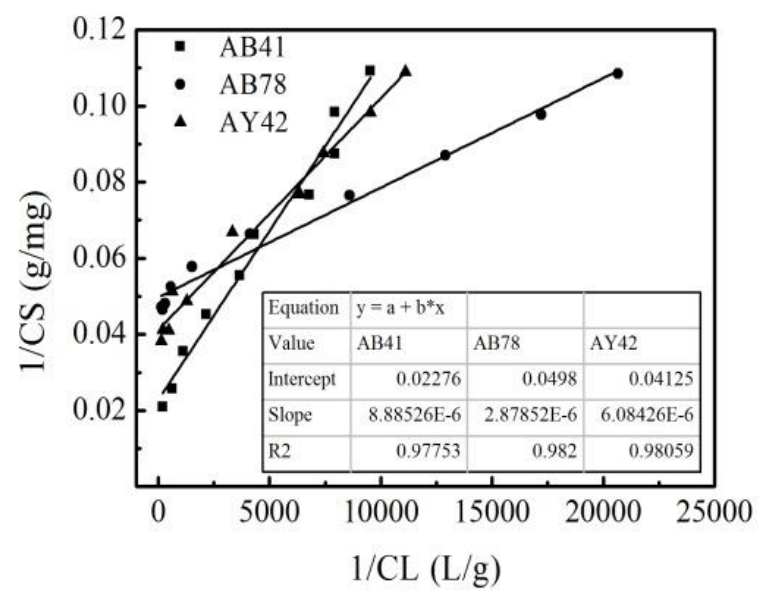

Figure 4. Determination of constants $\mathrm{S}$ and $\mathrm{K}$ used for Langmuir curve.

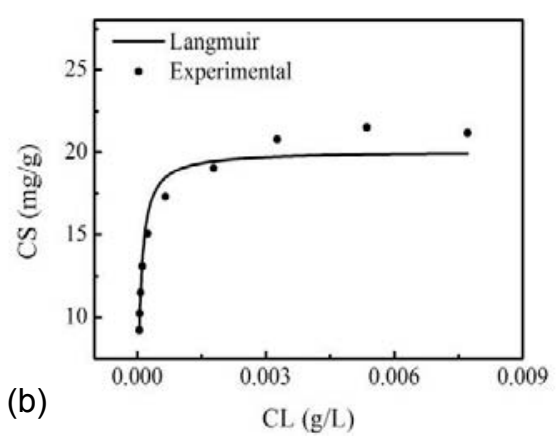

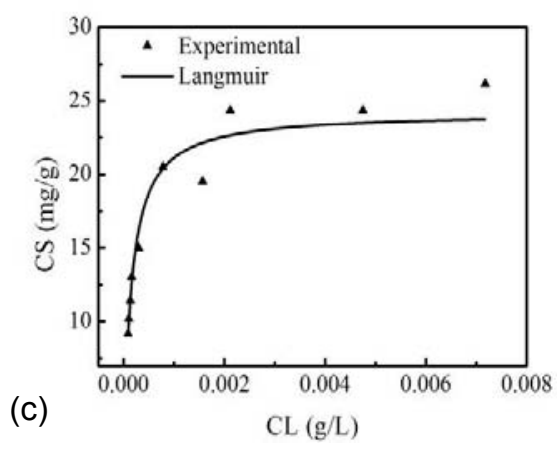

Figure 5. Experimental results and Langmuir sorption isotherm for three acid dyes: a) AB41; b) AB78; and c) AY42. 
in close agreement with the values and the shapes of the Langmuir isotherm, with very small or ignorable differences that could not be detected at times. AB41 had highest $C_{\mathrm{s}}$ values at equilibrium of about $50 \mathrm{mg} / \mathrm{g}$ followed by AY42 with values of about $26 \mathrm{mg} / \mathrm{g}$ and lastly AB78 with values of about $22 \mathrm{mg} / \mathrm{g}$. These results were in good agreement with $S$ values following exactly the same trend as the sorption capacity values $\left(C_{\mathrm{s}}\right)$. The main reason for this observation is that the two terms are directly proportional to each other according to the relationship by Langmuir isotherm.

\section{Conclusion}

All the dyes tested could follow the Langmuir isotherm of sorption such that the curves for the experiments and the ones for Langmuir isotherm could be comparable with very small differences. The results also showed that $A B 41$ had the highest values of sorption capacity compared with $A B 78$ and AY42; this was because of the highest saturation value $(S)$ compared with the other two.

\section{References}

[1] Wong, Y.C., et al., Equilibrium studies for acid dye adsorption onto chitosan. Langmuir, 2003;19(19):pp. 7888-7894.

[2] Akbari, A., J.C. Remigy, and P. Aptel, Treatment of textile dye effluent using a polyamide-based nanofiltration membrane. Chemical Engineering and Processing, 2002;41(7):pp. 601-609.

[3] Ahmed, M., et al., Effect of structural properties of acid dyes on their adsorption behaviour from aqueous solutions by amine modified silica. Journal of Hazardous Materials, 2009;161:pp. 1544-1550.

[4] Laasri, L., M.K. Elamrani, and O. Cherkaoui, Removal of two cationic dyes from a textile effluent by filtrationadsorption on wood sawdust. Environmental Science and Pollution Research, 2007;14(4):pp. 237-240.

[5] Chakraborty, S., et al., Nanofiltration of textile plant effluent for color removal and reduction in COD. Separation and Purification Technology, 2003;31(2):pp. 141-151.

[6] Erdumlu, N., et al., Reuse of effluent water obtained in different textile finishing processes. Autex Research Journal, 2012;12(1):pp. 23-28.
[7] Vandevivere, P.C., R. Bianchi, and W. Verstraete, Treatment and reuse of wastewater from the textile wetprocessing industry: review of emerging technologies. Journal of Chemical Technology and Biotechnology, 1998;72(4):pp. 289-302.

[8] Lin, S.H. and C.M. Lin, Treatment of textile waste effluents by ozonation and chemical coagulation. Water Research, 1993;27(12):pp.1743-1748.

[9] Walker, G.M. and L.R. Weatherley, Adsorption of acid dyes on to granular activated carbon in fixed beds. Water Research, 1997;31(8):pp. 2093-2101.

[10] Ganesh, R., G.D. Boardman, and D. Michelsen, Fate of azo dyes in sludges. Water Research, 1994;28(6):pp. 1367-1376.

[11] Chu, W. and S.M. Tsui, Photo-sensitization of diazo disperse dye in aqueous acetone. Chemosphere, 1999;39(10):pp. 1667-1677.

[12] Chiou, M.S. and G.S. Chuang, Competitive adsorption of dye in acid solutions on chemically metanil yellow and RB15 cross-linked chitosan beads. Chemosphere, 2006;62(5):pp. 731-740.

[13] Dong, Y.A., et al., Ultrafiltration enhanced with activated carbon adsorption for efficient dye removal from aqueous solution. Chinese Journal of Chemical Engineering, 2011;19(5):pp. 863-869.

[14] Kosmider, K. and J. Scott, Polymeric nanofibres exhibit an enhanced air filtration performance. Filtration \& Separation, 2002; 39(6):pp. 20-22.

[15] Basiri, F., et al., Recycling of direct dyes wastewater by nylon-6 nanofibrous membrane. Current Nanoscience, 2011;7(4):pp. 633-639.

[16] Burger, C., B.S. Hsiao, and B. Chu, Nanofibrous materials and their applications. Annual Review of Materials Research, 2006;36:pp. 333-368.

[17] He, J., Y. Liu, et al., eds. Electrospun nanofibres and their applications. 2008, Smithers; pp. 1-62.

[18] Huang, Z.M., et al., A review on polymer nanofibers by electrospinning and their applications in nanocomposites. Composites Science and Technology, 2003;63(15):pp. $2223-2253$.

[19] Ngcobo, P.S., Effects of temperature on sorption process using nanofibrous membrane. Faculty of Textile Engineering, Technical University of Liberec: Liberec. $p$. 104. 